\title{
Scarf pin inhalation: clinical characteristics and surgical treatment
}

Hicham Fenane ${ }^{1}$, Mohammed Bouchikh ${ }^{1,2^{*}}$, Khalid Bouti ${ }^{3}$, Mehdi EL Maidi ${ }^{1}$, Fahd Ouchen ${ }^{1}$, Tchely-Oaly Mbola ${ }^{1}$, Lamboni Damessane ${ }^{1}$, Abdellah Achir ${ }^{1,2}$ and Abdellatif Benosman ${ }^{1,2}$

\begin{abstract}
Objective: Scarf pin inhalation is becoming a frequent accident among young Moroccan woman who wears islamic veil. The aim of the study is to highlight indications, principles and challenges of surgical removal of that particular foreign body.

Methods: Twenty-eight patients were hospitalized in Thoracic Surgery department of Ibn Sina Hospital at Rabat between January 2008 and June 2013 for surgical removal of a pin scarf after unsuccessful endoscopy.

Results: Mean age was 20 years. Inhalation was accidental in all cases. Average interval between inhalation and surgery was 10 days. Penetration syndrome was found in $82 \%$ of patients. Pin was located at the left tracheo-bronchial tree in $53.5 \%$ of cases and at the right one in $46.4 \%$. All were operated by thoracotomy. Surgery was conservative in all cases, and postoperative course was uneventful.

Conclusion: In case of failure endoscopic treatment, surgery remains the only alternative. It must be as conservative as possible. Short interval between inhalation accident and surgery prevents parenchymal resection.
\end{abstract}

Keywords: Hairpin, Foreign body, Inhalation, Bronchoscopy, Thoracotomy

\section{French abstract}

Introduction: L'inhalation d'épingle à foulard est un accident de plus en plus fréquent chez la jeune femme marocaine qui porte le voile islamique. Le but de ce travail est de mettre le point sur indications, les principes et les difficultés de la chirurgie de ce corps étranger particulier.

Méthodes: Vingt-huit patientes étaient hospitalisées au service de Chirurgie Thoracique de l'hôpital Ibn Sina de Rabat entre janvier 2008 et juin 2013 pour extraction chirurgicale d'une épingle à foulard après échec de l'endoscopie.

Résultats: La moyenne d'âge était de 20ans. L'inhalation était accidentelle dans tous les cas. Le délai moyen entre l'inhalation et la chirurgie était de 10 jours. Le syndrome de pénétration était retrouvé chez 82\% des patientes. L'épingle était localisée au niveau de l'arbre trachéo-bronchique gauche dans 53,5\% des cas et à droite dans $46,4 \%$ des cas. La voie d'abord était une thoracotomie et aucune résection parenchymateuse n'était nécessaire.

Conclusion: La chirurgie ne doit être une alternative au traitement endoscopique qu'en cas d'échec de ce dernier. Elle se doit d'être conservatrice autant que possible. Le court délai entre l'accident d'inhalation et la chirurgie permet d'éviter les résections parenchymateuses.

Mots-clés: Epingle, Corps étranger, Inhalation, Bronchoscopie, Thoracotomie

\footnotetext{
* Correspondence: m.bouchikh@um5s.net.ma

'Department of Thoracic Surgery, Ibn Sina University Hospital, BP 353, Rabat

Principale 10001, Morocco

${ }^{2}$ Unit of pedagogy and research in Thoracic Surgery, Faculty of Medicine and

Pharmacy, University Mohamed V, Rabat, Morocco

Full list of author information is available at the end of the article
} 


\section{Background}

Foreign body (FB) inhalation is a serious problem that usually happens to children $[1,2]$. The type of FB depends on regions, eating habits and even clothing habits. Scarf pin is a particularly common FB in Islamic countries where women wear veil $[3,4]$.

We present a series of 28 cases of scarf pin, operated in Thoracic Surgery Department of Ibn Sina hospital in Rabat. We would like to highlight indications, principles and challenges of surgical removal of this FB.

\section{Methods}

Between January 2008 and June 2013, 28 patients were operated in our department for surgical removal of a scarf pin inhaled by accident.

Average age was 20 years. No favoring factor (swallowing disorder, neurologic, neuromuscular or metabolic disorder) was found. All patients received a chest radiograph to localize the radio-opaque pins. Radiography was repeated right before surgery to verify possible migration of the pin.

Patients requested surgical treatment after repeated, unsuccessful flexible bronchoscopy removal, on an average 2.5 attempts per patient. Seven patients underwent rigid bronchoscopy as well. This failure was due to very distal migration of pins and/or their embedding in the bronchus wall. The patients received antibiotics, and in 10 cases an additional short-term steroid treatment was included.

The study was approved by the ethics committee of the unit of pedagogy and research in Thoracic surgery at the Faculty of Medicine and Pharmacy of Rabat, Morocco.

\section{Results}

The foreign body was a $2-3 \mathrm{~cm}$ long metallic scarf pin, pointed on one end and with a spherical plastic cover on the other. Inhalation happened accidentally while arranging the scarf with both hands and holding the pin by its plastic end between teeth. Our patients reported that they were speaking, coughing, laughing or taking a deep breath when the accident happened.

Average delay between inhalation and surgery was 10 days, the shortest period being 3 days and the longest 21 days. Penetration syndrome was found in 23 patients, meaning $82 \%$ of cases. Slight hemoptysis was reported in 6 patients.

Chest radiograph was sufficient to determine the diagnosis, showing the pin in form of a linear opacity (Figure 1). It allowed us to localize pins that were found on the right side in 13 cases, and on the left in 15 cases. Inferior lobe was the most common location of pins (Table 1).

All patients were operated by posterolateral thoracotomy under general anesthesia with elective intubation. The intraoperative pin's localization was based on careful palpation of lung parenchyma searching for the plastic ending. It is usually easy to find when the affected lung is

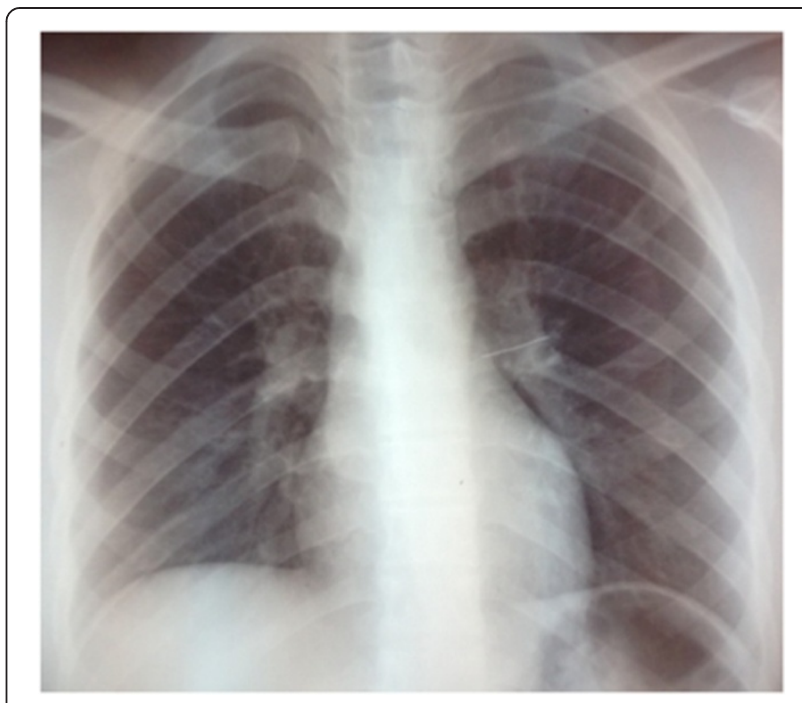

Figure $\mathbf{1}$ Chest radiograph showing a pin located in left superior lobar bronchus.

collapsed. However, palpation alone was insufficient in 7 patients and additional intraoperative radioscopy was necessary in 5 cases and flexible bronchoscopy in 2 cases.

In all cases, surgery was conservative and no parenchymal resection was necessary. Removal of pins was performed by incision of the parenchyma or pneumotomy (Figure 2) in 16 patients who had peripheral FBs and by bronchotomy in 12 cases where FBs were central and/or embedded in the bronchus wall.

Post-operative recovery was uneventful in $90 \%$ of patients. Three patients have shown air leaking for more than 5 days. Average length of postoperative drainage was 3 days.

\section{Discussion}

Foreign body (FB) inhalation is a serious accident that happens most commonly to children 3-4 years old and to adults above 50 years old, as they have tendency to swallowing disorders $[1,5]$. The nature of foreign body varies according to age, regions, eating habits and even clothing habits $[1,2,4]$. In our series all patients were young, 20 years old on average, which reflects data found in literature $[1,2,4,5]$. They were all wearing veil and inhalation was by accident while patients tried to place pins in their scarf and held one or more pins between their teeth $[1,5]$. Most patients reported that they were speaking, coughing,

Table 1 Distribution of pins in the tracheobronchial tree

\begin{tabular}{ll}
\hline Right lung: $\mathbf{1 3}$ pins, being $\mathbf{4 3 . 5 \%}$ & Left lung: $\mathbf{1 5}$ pins, being $\mathbf{5 6 . 5 \%}$ \\
\hline Superior lobe: 1 & Culmen: 2 \\
Middle lobe: 1 & Lingula: 2 \\
Inferior lobe: 10 & Inferior lobe: 9 \\
Main bronchus: 1 & Main bronchus: 2 \\
\hline
\end{tabular}




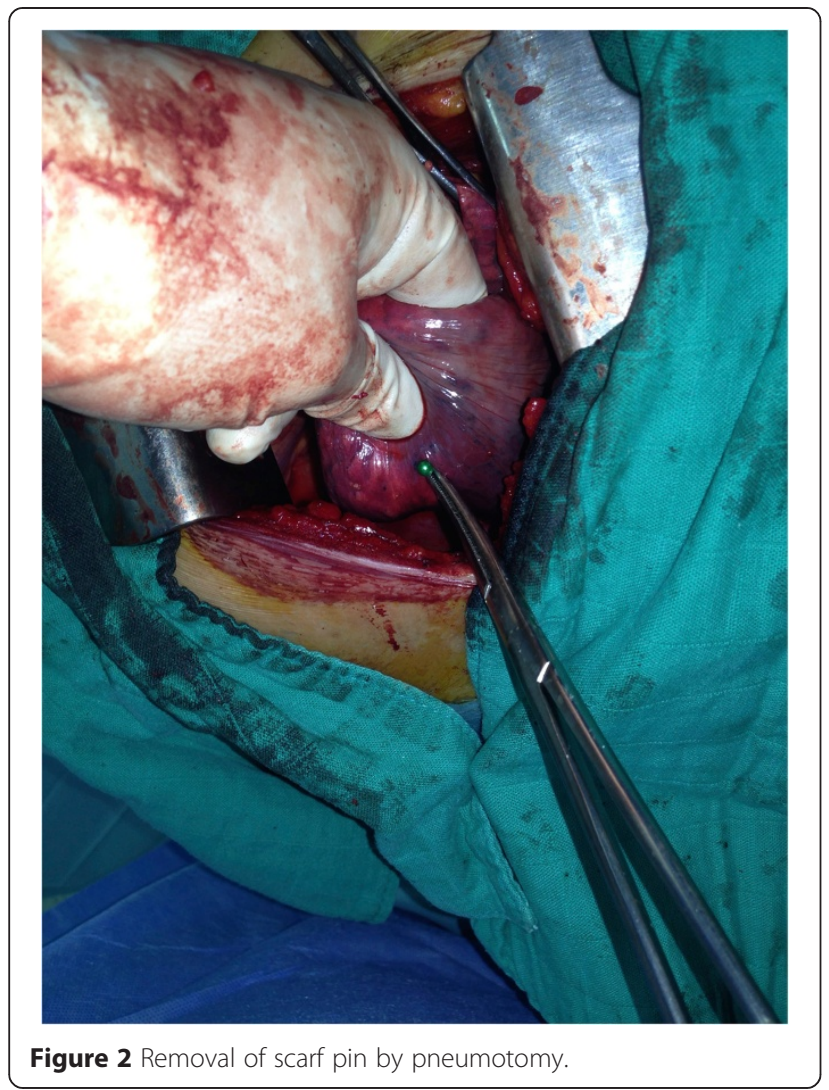

laughing or taking a deep breath at the time of accident. Their young age and lack of experience in arranging the veil played a favoring role as well $[1,5]$.

Due to slender shape of pins, inhalation is never asphyxiating. Symptomatology can be summarized as a penetration syndrome (coughing fits, suffocation and dyspnea) [1,3,5]. In our series that syndrome was present in $82 \%$ of cases. These symptoms fade after a few minutes. Zaghba [5] and A. Hebbazi [1] experienced similar findings in their series. According to literature, the rate of asymptomatic patients is between $10 \%$ and $20 \%[1,6]$.

Complications of intrabronchial FB are obstructive emphysema, recurrent pneumopathy, bronchiectasis, pulmonary abscess, pleural effusion or even pneumomediastinum [7-9]. These complications are more common if delay between inhalation of FB and its removal is prolonged $[5,8]$. As pins are slender and metallic, they do not favor stasis, surinfections and parenchymal destructions. It explains the absence of all these complications in our patients. Otherwise, FBs embedded in the bronchial mucous membrane cause inflammatory reaction with granuloma formation around the FB which makes its endoscopic removal extremely difficult $[1,5]$.

Chest radiograph is a simple and efficient test to determine diagnosis $[1,5]$. It was sufficient to diagnose our patients, as pins were shown as linear opacity.
Contrary to results of other authors [1,4,5], location of pins in left tracheobronchial tree was slightly predominant in our series; 15 cases (53.5\%) as opposed to $46.5 \%$ on the right side. Frequency of left localization in our series can be explained by relatively easy endoscopic removal of pins located on the right. As a result, more patients with pins on left side needed surgical removal.

Flexible bronchoscopy is the best therapeutic means [10]. Preferably, it should be performed urgently before complications arise $[11,12]$. Success rate of this treatment varies according to authors: $56 \%$ for Al-Ali, $62.5 \%$ for Hebbazi and $80.6 \%$ for Zeghba $[1,5,13]$. In our series, average number of attempts of flexible bronchoscopy removal was 2.5 times per patient. It is difficult to estimate success rate of endoscopic removal as our patients came from different centers of Rabat region. In case of unsuccessful flexible bronchoscopy, rigid bronchoscopy may be very helpful [2]. It was used in case of 7 patients in our series. Reasons of unsuccessful endoscopy were: distal localization favored by characteristic shape of this FB, pins embedded in bronchus wall with inflammatory reaction.

In case of unsuccessful endoscopy, surgery is indicated. The rate of need for surgery in literature varies from 1.6 to $18 \%[6,7,14,15]$. All our patients were operated by posterolateral thoracotomy. Choice of surgical procedure depends on the location of FB and the time since the inhalation. Pneumotomy, bronchotomy and parenchymal resections are the different surgical procedures [4,7]. In our series, treatment was always conservative, no resection was used.

In case of peripheral pins, perioperative localization by simple palpation of collapsed lung, was generally easy. In difficult cases, localization through endoscopy or radioscopy can be useful. These techniques were used in 7 of our patients.

\section{Conclusion}

Scarf pin is a particular type of tracheobronchial foreign body. Preferred treatment is endoscopic removal. It has to be performed as soon as possible. Surgery is an alternative in case of unsuccessful endoscopy. It is associated with low morbidity. It has to be conservative as much as possible. Localization by careful palpation of collapsed lung parenchyma is the principal technique of this procedure. Perioperative radioscopy or bronchoscopy can be useful.

\section{Consent}

Written informed consent was obtained from the patients for the publication of this report and any accompanying images.

\section{Competing interests}

The authors declare that they have no competing interests. 


\section{Authors' contributions}

HF: a-b-c; conception of the study, analysis and interpretation of data and drafting the manuscript. MB: a-c-d; conceived of the study, participated in drafting the manuscript and approved the final manuscript. KB: drafting the manuscript. ME: analysis and interpretation of data. FO: analysis and interpretation of data. TM: analysis and interpretation of data. LD: analysis and interpretation of data. AA: analysis and interpretation of data. AB: approved the final manuscript. All authors read and approved the final manuscript.

\section{Author details}

'Department of Thoracic Surgery, Ibn Sina University Hospital, BP 353, Rabat Principale 10001, Morocco. ${ }^{2}$ Unit of pedagogy and research in Thoracic Surgery, Faculty of Medicine and Pharmacy, University Mohamed V, Rabat, Morocco. ${ }^{3}$ Respiratory Department, Regional Hospital Center of Tetuan, Tetuan, Morocco.

Received: 23 December 2014 Accepted: 17 April 2015

Published online: 26 April 2015

\section{References}

1. Hebbazi A, Afif H, El Khattabi W, Aichane A, Bouayad Z. Scarf pin: a new intrabronchial foreign body. Rev Mal Respir. 2010;27:724-8.

2. El Koraïchi A, Mokhtari M, El Haddoury M, El Kettani SE. Rigid bronchoscopy for pin extraction in children at the Children's Hospital in Rabat, Morocco. Rev Pneumol Clin. 2011;67:309-13.

3. Hasdiraz L, Bicer C, Bilgin M, Oguzkaya F. Turban pin aspiration: non-asphyxiating tracheobronchial foreign body in young islamic women. Thorac Cardiovasc Surg. 2006:54:273-5.

4. Arsalane A, Zidane A, Atoini F, Traibi A, Kabiri EH. The surgical extraction of foreign bodies after the inhalation of a scarf pin: two cases. Rev Pneumol Clin. 2009:65:293-6.

5. Zaghba N, Benjelloun H, Bakhatar A, Yassine N, Bahlaoui A. Scarf pin: an intrabronchial foreign body who is not unusual. Rev Pneumol Clin. 2013;69:65-9.

6. Kaptanoglu M, Nadir A, Dogan K, Sahin E. The heterodox nature of "Turban Pins" in foreign body aspiration; the central anatolian experience. Int J Pediatr Otorhinolaryngol. 2007:71:553-8.

7. Caidi M, Kabiri H, Lazrek I, el Maslout A, Ben OA. Surgery for intra-bronchial foreign bodies. Ann Chir. 2002;127:456-60.

8. Mehta A, Sarin D. Subcutaneous emphysema: an unusual presentation of foreign body bronchus. Med J Armed Forces India. 2007;63:71-2.

9. Aggarwal S, Keshri A. Subcutaneous emphysema: an unusual presentation of an unsuspected foreign body bronchus in an adult patient. J Laryngol Voice. 2012;2:38.

10. Yüksek T, Solak H, Odabas D, Yeniterzi M, Ozpinar C, Ozergin U. Dangerous pencils and a new technique for removal of foreign bodies. Chest. 1992;102:965-7.

11. Üskül TB, Türker H, Arslan S, Selvi A, Kant A. Use of Fiberoptic Bronchcoscopy in Endobronchial Foreign Body Removal in Adults. Turk Respir J. 2007:8:39-43.

12. Al-Sarraf N, Jamal-Eddine H, Khaja F, Ayed AK. Headscarf pin tracheobronchial aspiration: a distinct clinical entity. Interact Cardiovasc Thorac Surg. 2009:9:187-90.

13. Al-Ali MAK, Khassawneh B, Alzoubi F. Utility of fiberoptic bronchoscopy for retrieval of aspirated headscarf pins. Respiration. 2007;74:309-13.

14. Kaptanoglu M, Dogan K, Onen A, Kunt N. Turban pin aspiration; a potential risk for young Islamic girls. Int J Pediatr Otorhinolaryngol. 1999;48:131-5.

15. Murthy PS, Ingle VS, George E, Ramakrishna S, Shah FA. Sharp foreign bodies in the tracheobronchial tree. Am J Otolaryngol. 2001:22:154-6.

\section{Submit your next manuscript to BioMed Central and take full advantage of:}

- Convenient online submission

- Thorough peer review

- No space constraints or color figure charges

- Immediate publication on acceptance

- Inclusion in PubMed, CAS, Scopus and Google Scholar

- Research which is freely available for redistribution

Submit your manuscript at www.biomedcentral.com/submit 